\title{
Experimental Study Regarding the Influence of Welding Parameters on the Mechanical Behavior of High Density Polyethylene Pipes
}

\author{
IBRAHIM RAMADAN, MARIA TANASE*
}

Petroleum-Gas University of Ploiești, Faculty of Mechanical and Electrical Engineering, Department of Mechanical Engineering, 39 Bucuresti Blvd., Ploiesti, Romania

Abstract: The experimental study conducted for this article was made using the butt fusion welding procedure for high density polyethylene (HDPE) pipes. PE100 (SDR 17, PN 10) water pipes were used, as for the experimental study parts of around 200 to $300 \mathrm{~mm}$ were welded, using different welding parameters. The influence of the welding parameters on the pipes resistance was analyzed, through visual examination and experimental tests such as tensile, bending and pressure tests.

Keywords: polyethylene, HDPE pipe, experimental tests, welding

\section{Introduction}

Polyethylene (PE) is one of the most known and used plastic materials. HDPE materials are often used to produce water or gas pipes. The main advantages of using HDPE pipes are corrosion and chemical resistance, simple mounting technology, good weldability even at low temperatures, low installation and maintenance costs, long service life - up to 100 years expected lifetime $[1,2]$.

In practice, in order to construct long pipes networks, it is important to join the short pipes, by using different methods as butt fusion welding, electrofusion welding and extrusion welding [3]. Due to the low cost and the simplicity of the procedure, the most used method for welding PE pipes is butt fusion welding [3].

Butt fusion involves the simultaneous heating of the ends of two pipe/fitting components which are to be joined, until a molten state is attained on each contact surface.

The two surfaces are then brought together under controlled pressure for a specific cooling time and a homogeneous fusion joint is formed. The resultant joint is fully resistant to end loads and has comparable performance under pressure to the pipe itself.

An electrical heater plate is used to raise the temperature of the pipe ends to the required fusion temperature.

During the fusion process internal and external 'weld beads' are formed. Techniques have been developed to minimize the size of the beads, however as they do not add anything to the overall strength they may be safely removed if required. The removed weld beads can be inspected as part of a quality control programme [4].

The quality of the welded joint is evaluated using both nondestructive and destructive testing (visual inspection, tensile and bending testing of joints).

\section{Materials and methods}

In order to determine the welding behavior of HDPE pipes, 5 meters of water pipe with the following characteristics were used: PE 100 (SDR 17, PN10, OD = $90 \mathrm{~mm}$ ). The pipes were cut (Figure 1) and subsequently machined at the ends, in order to weld the pipes, using different welding parameters (Figure 2).

\footnotetext{
*email: maria.tanase@upg-ploiesti.ro
} 


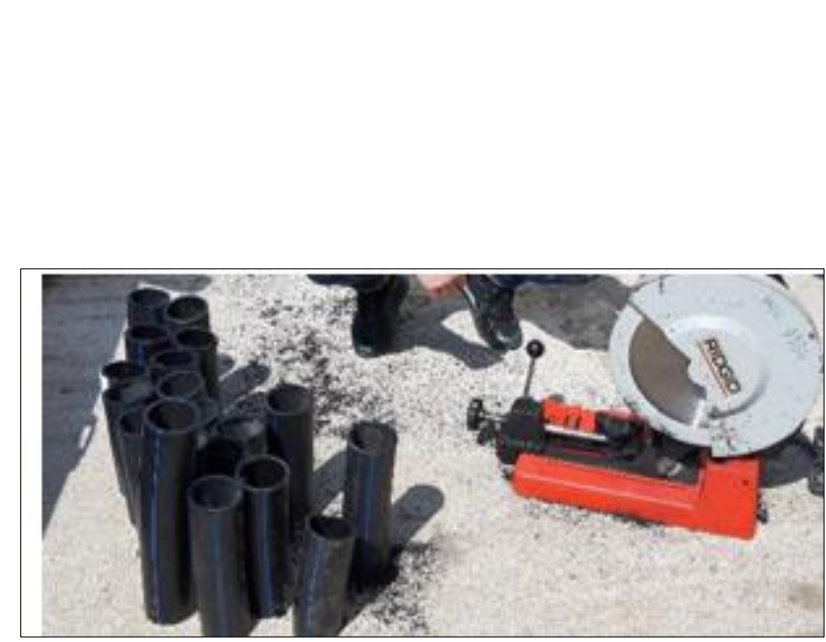

Figure 1. The pipes used for experimental study

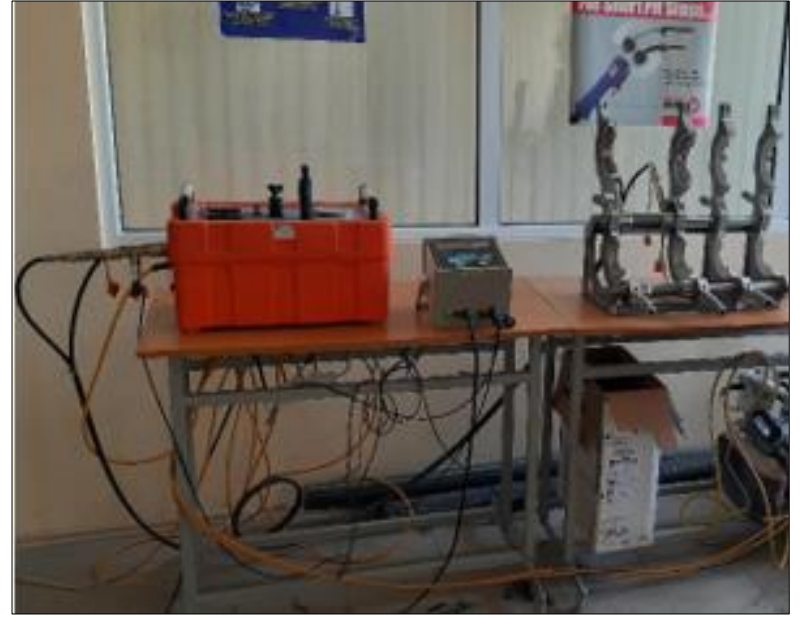

Figure 2. Work device for welding pipes

The welding parameters were chosen following the instructions given by the manufacturers of such plastics [5]. Due to the fact that the working machine did not allow the change of the plate temperature, it was chosen as a study variant, welding at a temperature of $220^{\circ} \mathrm{C}$, using different times period $(45$ ", 60 ", 90 ").

It was chosen as an additional study variant, the case of cold HDPE pipe. Thus, two of the samples were cooled accelerated with ice, subsequently being stored in a refrigerated box at a temperature of $15{ }^{0} \mathrm{C}$, for a period of about 20 days (Table 1, sample 60R).

Table 1. The welding parameters for the tested pipes

\begin{tabular}{|c|c|c|c|c|}
\hline Sample & $\begin{array}{c}\text { Heating } \\
\text { temperature, } t\left[{ }^{0} \mathrm{C}\right]\end{array}$ & $\begin{array}{l}\text { Time required for } \\
\text { welding, } \tau[s]\end{array}$ & $\begin{array}{c}\text { Welding } \\
\text { pressure, } P \\
\text { [bar] }\end{array}$ & Cooling conditions \\
\hline 45 & \multirow{4}{*}{220} & 45 & \multirow{4}{*}{15} & Slow cooling in the air \\
\hline 60 & & 60 & & Slow cooling in the air \\
\hline $60 \mathrm{R}$ & & 60 & & Accelerated cooling in ice \\
\hline 90 & & 90 & & Slow cooling in the air \\
\hline
\end{tabular}

A number of two samples (welded in the same conditions) were made - one used for tensile, bending, and visual examination - and one for pressure tests (Figure 3).

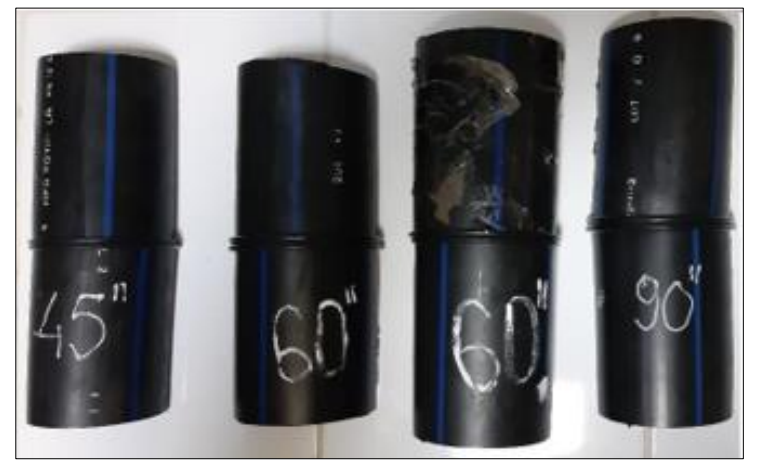

Figure 3. The welds used for the visual examination

To check the quality of welded joints, the technical prescription CR9-2013 recommends the visual inspection and the tensile test. Within the experimental program, for a better assessment of the quality of welded joints, a series of additional tests (bending test and pressure test) were performed. 


\section{Results and discussions}

\section{A.Visual inspection}

The literature recommends several criteria for accepting or rejecting a weld in visual examination [5, 6]. The main unacceptable defects are related to the misalignment or the use of inadequate welding parameters.

The misalignment is the main factor leading to major welding defects. Although the placement is done end to end, including in the field, with a special device that has the ability to correct the misalignment and ovality, it is not considered that, due to the delivery of the pipes - in most cases coils of $200 \mathrm{~m}$, when the clamps of the device are removed, the pipes tend to regain their oval shape so that obvious welding defects will appear. Particular attention will be paid to the observation of the nonuniformity of the weld around the pipe and of the different reinforcements on those two joint ends.

Excessive joint force, overheating and other aspects that depend exclusively on the operator or work equipment lead to improper weld reinforcements (Figure 4).

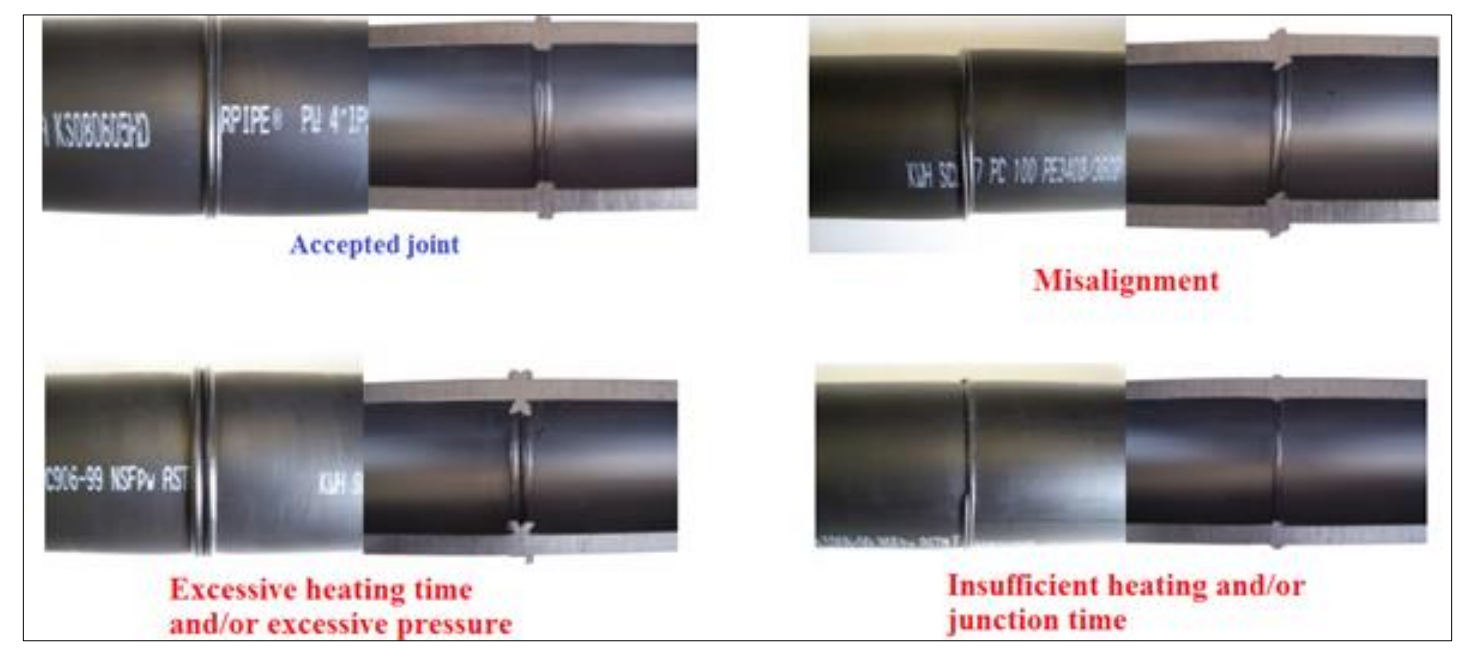

Figure 4. Accepted / rejected HDPE pipe joints [6]

The visual inspection revealed the pipes misalignment and excessive forces were applied to the joints, as can be seen in Figure 5.

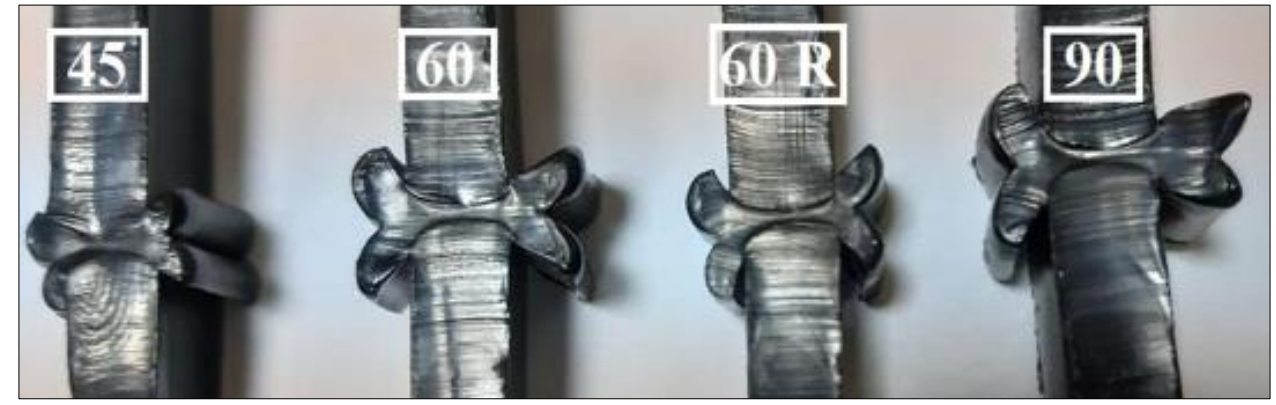

Figure 5. Details of welded joints obtained in the experiments

The primary visual examination is not sufficient as additional criteria are needed to be able to assess the quality of the welds made.

For a further evaluation of the quality of welded joints, the method according to Plastic Pipe Institute was used. Thus, the geometric elements of the welds were measured using the notations in Figure 6. 


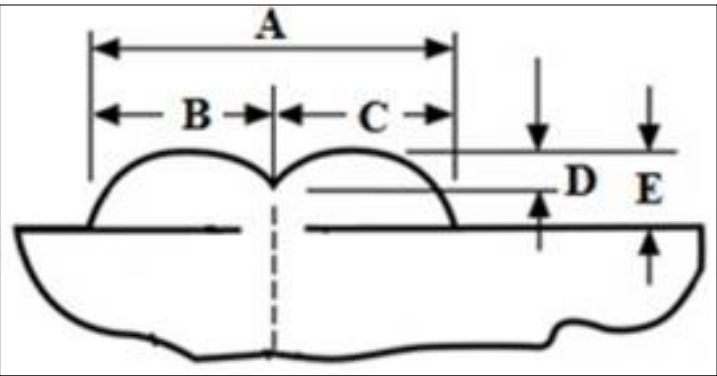

Figure 6. Proposed method for measuring the welds geometry

The results obtained are presented in Table 2.

Table 2. The measured geometry of the welds

\begin{tabular}{|c|c|c|c|c|c|}
\hline \multirow{2}{*}{ Sample } & \multicolumn{2}{|c|}{ A } & B & C & \multicolumn{2}{c|}{ D } & \multicolumn{2}{c|}{ E } \\
\cline { 2 - 6 } & \multicolumn{2}{|c|}{$\mathbf{m m}$} & 2.61 & 1.13 & 2.74 \\
\hline $\mathbf{4 5}$ & 5.2 & 2.64 & 4.07 & 1.98 & 3.96 \\
\hline $\mathbf{6 0}$ & 7.87 & 3.80 & 3.25 & 1.86 & 3.78 \\
\hline $\mathbf{6 0 ~ R}$ & 6.31 & 2.15 & 4.69 & 2.12 & 4.28 \\
\hline $\mathbf{9 0}$ & 8.88 & 4.18 & 4 & 2 & 4 \\
\hline Optimal welding* & 8 & 4 & 4 & 2 & 4 \\
\hline
\end{tabular}

*according to Plastic Pipe Institute.

The measurement of the geometric characteristics of the welds shows significant deviations from an optimal weld.

\section{B.Tensile test}

The tensile test was performed in accordance with the specifications of ISO 527: 2012 - Plastics. Determination of Tensile Properties [7]. Two specimens were taken from each welded pipe and the main mechanical characteristics were determined on the Lloyd - LRX plus machine (Figure 7).

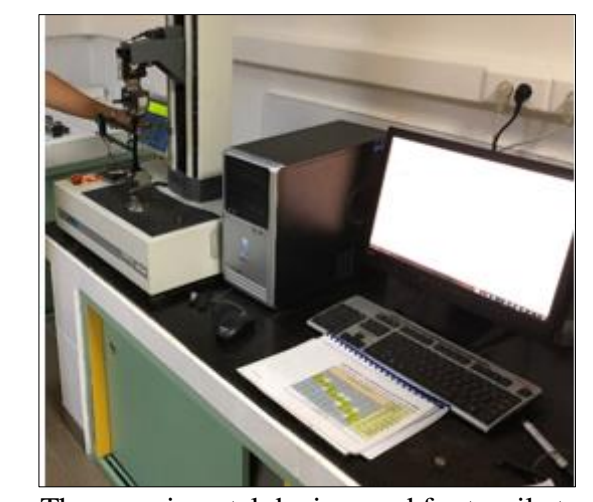

a.The experimental device used for tensile test

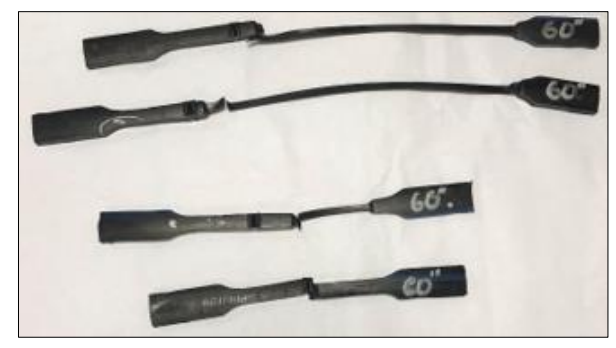

c. comparative aspect of some welded samples after the tensile test

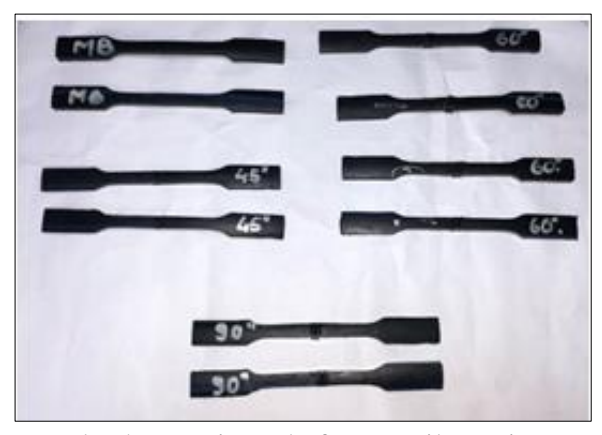

b.The specimen before tensile testing

Figure 7. Determination of mechanical properties by tensile test 
Table 3. Tensile test results

\begin{tabular}{|c|c|c|c|c|c|c|c|c|c|}
\hline Sample & $\boldsymbol{L}_{\boldsymbol{f}}, \mathbf{m m}$ & $\boldsymbol{L}_{\boldsymbol{i}}, \mathbf{m m}$ & $\boldsymbol{A}, \boldsymbol{\%}$ & $\boldsymbol{R}_{\boldsymbol{m}}, \mathrm{MPa}$ & Sample & $\boldsymbol{L}_{\boldsymbol{f}}, \mathbf{m m}$ & $\boldsymbol{L}_{\boldsymbol{i}}, \mathbf{m m}$ & $\boldsymbol{A}, \boldsymbol{\%}$ & $\boldsymbol{R}_{\boldsymbol{m}}, \mathrm{MPa}$ \\
\hline $\mathbf{4 5} \mathbf{a}$ & 370 & 80 & 362.5 & 32.50 & $\mathbf{6 0 R} \mathbf{a}$ & 200 & 80 & 150 & 17.87 \\
\hline $\mathbf{4 5} \mathbf{b}$ & 364 & 80 & 355 & 32.78 & $\mathbf{6 0 R} \mathbf{b}$ & 207 & 80 & 158.75 & 18.14 \\
\hline $\mathbf{6 0} \mathbf{a}$ & 378 & 80 & 372.5 & 31.62 & $\mathbf{9 0} \mathbf{a}$ & 312 & 80 & 290 & 26.75 \\
\hline $\mathbf{6 0} \mathbf{b}$ & 354 & 80 & 342.5 & 33.04 & $\mathbf{9 0} \mathbf{b}$ & 320 & 80 & 300 & 26.02 \\
\hline
\end{tabular}

Different welding parameters determined different mechanical characteristics in each welded joint. It can also be noted the increased fragility of the accelerated cooled welded joint, so it is recommended that this important aspect be taken into account in the field, requiring the creation of conditions to minimize possible defects that may occur after welding (Table 1).

\section{Bending Test}

The test was performed in accordance with the specifications of ISO 178: 2019 - Plastics. Determination of flexural properties [8]. It was chosen as a method 3 Point bending Test - practical, a portion is cut from the welded pipe to include the joint in the middle (Figure 8a, Figure 8b).

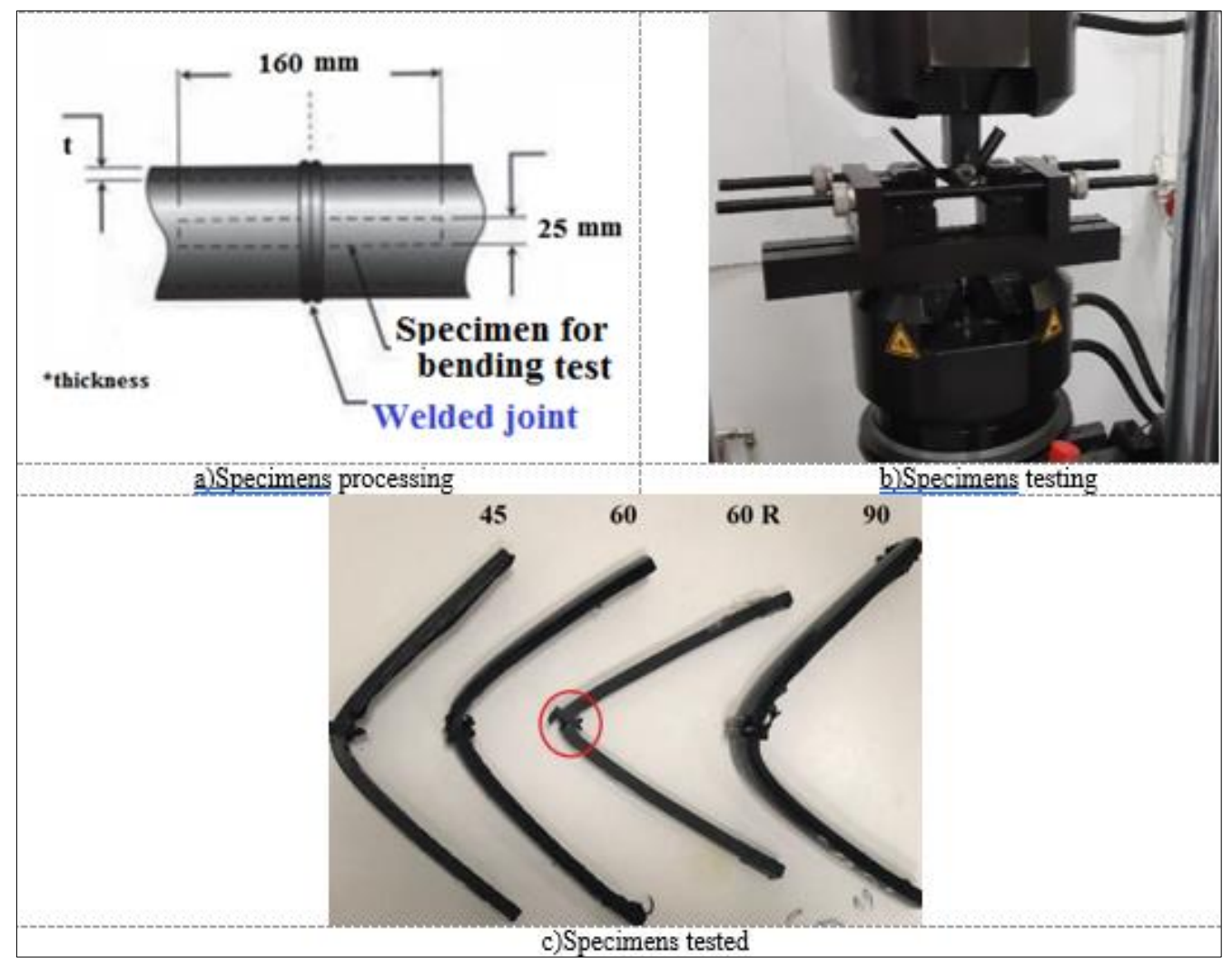

Figure 8. Bending test

The aspect of the specimens tested (FV Figure 8c) reveals the following aspects:

- pipes whose welded joints were cooled rapidly, behaved brittle, the weld being rigid, which led to the rupture of the joint, an element that strengthens the conclusions drawn from the tensile tests;

- in all other joints (with slow cooling), a ductile behavior of the weld was observed, which bends without breaking at angles whose values are significantly lower than the minimum value allowed in the standard for the respective test. 


\section{D.Pressure Test}

For this experiment, it was used an experimental assembly consisting of compressor, pump, working pipe and sealing caps. The pressure was recorded with a manometer (Figure 9).

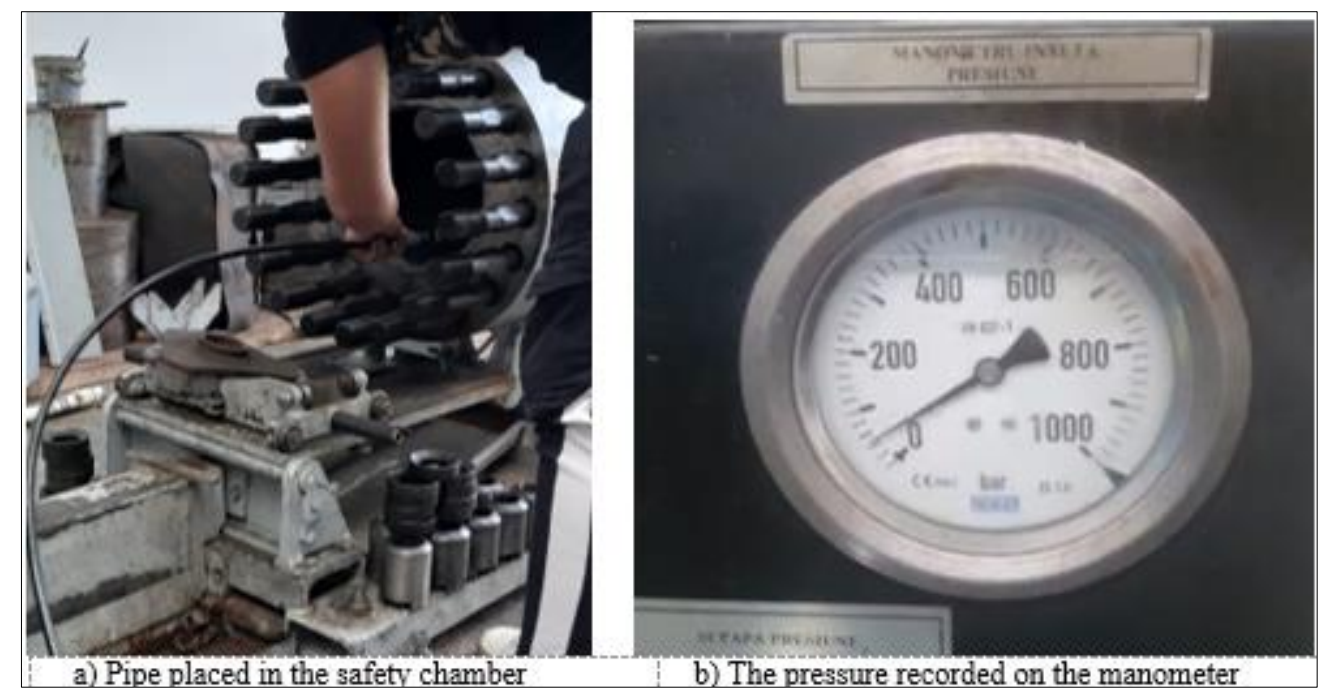

Figure 9. Pressure test

The pressure tests results reveal that the samples 45 ", 60 ", 90 " did not yield, being able to withstand a pressure of 40bar (Figure 9b) without leaks, so that the welding result is declared satisfactory, contrary to the aspects discovered during the visual examination. The 60R sample was the only one to which the welding failed, although the visual examination did not indicate problems.

\section{Conclusions}

After performing the tests, the following aspects were found:

- pipes whose welded joints have been cooled rapidly, have become fragile, the welding being rigid, which has led to the rupture of the joint, an element that strengthens the conclusions drawn from the tensile tests;

- in all other joints (with slow cooling), a ductile behavior of the weld was observed, these bending without breaking at angles whose values are significantly lower than the minimum value allowed in the standard for the respective test;

- if the work is carried out in conditions that would lead to an accelerated cooling of the welds, additional measures will be taken to prevent problems that may arise in such conditions;

- it is recommended that during the welding, the position of the pipes to be seriously respected, but also the duration of maintaining the heating plate on the pipes in order to achieve proper welded joints.

- the lower values obtained at tensile tests for the samples that had the maximum welding time raised some questions, so further studies will be conducted in this direction.

\section{References}

1.ALANAAF A., MOHAMED D., The Effect of Thickness and Temperature on the Burst Pressure of HDPE Pipes, Materials Science, 2017.

2.POPESCU, M., ARGESANU, V., JULA, M., Problems Associated with PEHD Welding, Mater. Plast. 43(4), 2006, 324- 329.

3.POKHAREL P., YOONSANG K., SUNWOONG, C., Microstructure and Mechanical Properties of the Butt Joint in High Density Polyethylene Pipe, International Journal of Polymer Science, 2016.

4.***https://www.pe100plus.com/PE-Pipes/Technical-guidance/model/Construction/methods/What-isbutt-fusion-hdpe-welding-i290.html

5.***Technical Letter Report Preliminary Assessment of NDE Methods on Inspection of HDPE Butt 
Fusion Piping Joints for Lack of Fusion JCN N6398, Task 2D S. L. Crawford S. E. Cumblidge S. R. Doctor T. E. Hall M. T. Anderson May 2008 Prepared for the U.S. Nuclear Regulatory Commission under U.S. Department of Energy Contract DE-AC05-76RL01830.

6.***UPONOR TECHNICAL BULLETIN - Butt Fusion, Joining Procedure and Qualification Guide, Canada, 2016.

7.***ISO 527: 2012 - Plastics. Determination of tensile properties.

8.***ISO 178: 2019 - Plastics. Determination of flexural properties

Manuscript received: 10.08 .2020 